\title{
SERUM URIC ACID AND HYPERTENSIVE COMPLICATIONS
}

\author{
Archana1, Sanjeev Kumar Singh ${ }^{2}$
}

${ }_{1}^{1}$ Assistant Professor, Department of Medicine, Rama Medical College, Mandhana, Kanpur, Uttar Pradesh, India.

${ }^{2}$ Assistant Professor, Department of Orthopaedics, Rama Medical College, Mandhana, Kanpur, Uttar Pradesh, India.

\section{BACKGROUND}

ABSTRACT

The objectives of this study were- 1 . to determine the relationship between raised serum uric acid levels with various complications related to hypertension, and 2. To determine as to whether raised serum uric acid levels could be an independent risk factor in essential hypertension.

\section{MATERIALS AND METHODS}

This observational study was carried out in RMC Kanpur. The study period was from 2016 to 2018. A total of 400 patients were studied of which 200 were cases (hypertensive patients) and 200 were controls (non-hypertensives). If they were having any other condition known to cause raised serum uric acid levels \& secondary hypertension, they were excluded. Hypertensive group was further sub-categorized into two groups stage 1 (H1) and stage 2 (H2) based on stage of hypertension (According to JNC VII classification of hypertension).

\section{RESULTS}

The study showed statistically significant $(\mathrm{p}=0.001)$ elevation of SUA levels in cases (patients having hypertension, when compared to that of controls). Also, a positive correlation was found between the severity of hypertension and the duration of hypertension.

\section{CONCLUSION}

There can be a direct association between raised serum uric acid levels and hypertension. Also, the study showed that the serum uric acid levels were significantly increased in patients with Stage 2 hypertension and those with a longer duration of hypertension in comparison with those with stage 1 hypertension and with those having hypertension less than 5 years respectively. Hence on the basis of study, we conclude that "serum uric acid can be used as a prognostic risk factor in essential hypertension."

\section{KEY WORDS}

Albinuria, Retinopathy, Nephropathy, Hyperuricaemia, Echocardiography, Incidence, Cerebrovascular Accident, Left Ventricular Hypertrophy

HOW TO CITE THIS ARTICLE: Archana, Singh SK. Serum uric acid and hypertensive complications. J. Evolution Med. Dent. Sci. 2019;8(09):559-561, DOI: 10.14260/jemds/2019/124

\section{BACKGROUND}

Hypertension is one of the leading causes of global burden of disease. Approximately 7.6 million deaths (13-15\% of total) and 92 million disability adjusted life years worldwide were attributable to high blood pressure in 2001. Raised serum uric acid concentrations in the blood are commonly encountered in essential hypertension.

Uric acid, which serves no biochemical function other than being an end product of purine metabolism, was first discovered in $1776 .{ }^{1}$ A Swedish chemist Scheele isolated it from a urinary tract stone. As such, raised serum uric acid levels are not considered a true risk factor for hypertension by the Joint National Committee, nor is it considered a cardiovascular risk factor by most expert organizations. Recent studies have challenged this long-standing theory. Some studies have reported that hyperuricaemia can predict the development of hypertension even in individuals lacking features of the metabolic syndrome.2,3

'Financial or Other Competing Interest': None.

Submission 24-05-2018, Peer Review 18-02-2019,

Acceptance 22-02-2019, Published 04-03-2019.

Corresponding Author:

Dr. Sanjeev Kumar Singh,

26 B, Jawahar Puram Shyam Nagar,

Kanpur-208015, Uttar Pradesh, India.

E-mail: sanjeev23021985@gmail.com

DOI: $10.14260 /$ jemds $/ 2019 / 124$

We had done this study to observe if there is any direct association between raised serum uric acid level and essential hypertension excluding renal, cardiovascular and metabolic syndrome in an Indian background 4 .

\section{Aim of The Study}

To study the association of serum uric acid levels with various complications of hypertension.

\section{MATERIALS AND METHODS}

This is an observational study. 200 cases (patients) of essential hypertension which were subcategorized into $\mathrm{H} 1$ and $\mathrm{H} 2$ depending on stage of hypertension (According to JNC VII classification of hypertension) and duration of hypertension into more than 5 years and less than 5 years, who are attending the OPD in RMC KANPUR during the study period of DEC 2016 to APRIL 2018.

Controls were patients who are non- hypertensive or suffering with any other condition known to cause hyperuricaemia. Serum uric acid was measured by using.

\section{Uricase / PAP Method}

Uric acid + H20 Uricase Allantoin + H2O H2O2 + Phenolic chromogens Peroxidase Red coloured compound. 


\section{Statistical Analysis}

Data was analysed using SPSS 16.0 software and chi square test. The qualitative data were expressed as numbers (\%)

\section{RESULTS}

The total no. of patients with hyperuricaemia in hypertensive group were 107 and normouricaemia 93.

\begin{tabular}{|c|c|c|c|}
\hline Complication & $\begin{array}{c}\text { Stage I } \\
\text { (H1) }\end{array}$ & $\begin{array}{c}\text { Stage II } \\
\text { (H2) }\end{array}$ & Total \\
\hline $\begin{array}{c}\text { 1 Fundus } \\
\text { (Hypertensive Retinopathy) }\end{array}$ & 13 & 52 & 65 \\
\hline 2 Albuminuria & 8 & 44 & 52 \\
\hline $\begin{array}{c}\text { 3 Raised Serum Creatinine } \\
\text { (Creatinine Clearance) }\end{array}$ & 28 & 45 & 73 \\
\hline 4 CVA & 5 & 10 & 15 \\
\hline 5 Cardiac (ECG + ECHO) & 8 & 20 & 28 \\
\hline
\end{tabular}

Table 1. Distribution of Patients According to Complication

\begin{tabular}{|c|c|c|c|c|}
\hline 节 & 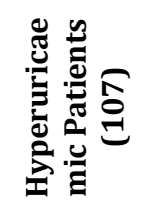 & 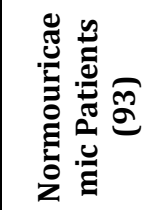 & 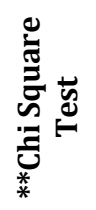 & $\frac{a^{*}}{\sum^{\frac{\pi}{J}}}$ \\
\hline $\begin{array}{c}1 \text { Fundus } \\
\text { (Hypertensive } \\
\text { retinopathy) }\end{array}$ & $42(39 \%)$ & $23(24 \%)$ & 4.782 & 0.02 \\
\hline 2 Albuminuria & $35(32 \%)$ & $17(18.2 \%)$ & 4.4 & 0.01 \\
\hline $\begin{array}{l}3 \text { Raised Serum } \\
\text { Creatinine } \\
\text { (Creatinine } \\
\text { Clearance) }\end{array}$ & $46(42 \%)$ & 27 (29\%) & 3.8 & 0.04 \\
\hline $4 \mathrm{CVA}$ & $13(12 \%)$ & $2(2.6 \%)$ & 7.17 & 0.007 \\
\hline $\begin{array}{c}5 \text { Cardiac (ECG + } \\
\text { ECHO) }\end{array}$ & $24(9 \%)$ & $4(4.3 \%)$ & 11.63 & 0.006 \\
\hline
\end{tabular}

Out of 107 hyperuricaemic patients of hypertensive group $39 \%$ patients developed hypertensive retinopathy while only $24 \%$ patients developed hypertensive retinopathy of normouricaemia group.

Hyperuricaemic patients significantly developed more hypertensive retinopathy in comparison to normouricaemic patients $\left({ }^{*} \mathrm{p}<0.02 ;{ }^{* *}\right.$ chi square test).

In our study $32 \%$ of hyperuricaemic patients developed albuminuria while only $18.2 \%$ of normouricaemic patients developed albuminuria $\left({ }^{*} \mathrm{p}<0.01\right.$; ${ }^{* *}$ chi square test) showing that hyperuricaemic patients of hypertension group developed more albuminuria in comparison to normouricaemic group.

$42 \%$ of hyperuricaemic patients of hypertensive group developed renal complications in the form of raised serum creatinine (Creatinine clearance) while only 29\% patients developed renal complications (Creatinine clearance) from normouricaemic group.

Thus, Hyperuricaemic patients significantly develops more renal complications in comparison to normouricaemic patients $\left({ }^{*} \mathrm{p}=0.04 ;{ }^{* *}\right.$ chi square test $)$.

Out of 107 patients of hypertensive group $12 \%$ developed CVA while only $2.6 \%$ normouricaemic patients developed CVA $\quad\left({ }^{*} \mathrm{p}=0.007 ; \quad{ }^{* *}\right.$ chi square test $)$ showing that hyperuricaemic patients significantly developed CVA in comparison to normouricaemic patients.
In our study $9 \%$ of hyperuricaemic patients of hypertensive group developed cardiac complications which include both (ECG and ECHO) while 4.3\% normouricaemic patients developed cardiac complications.

Hyperuricaemic patients significantly developed more cardiac complications in comparison to normouricaemic patients $\left({ }^{*} \mathrm{p}=0.006 ;{ }^{* *}\right.$ chi square test).

\section{DISCUSSION}

Hypertension is one of the leading causes of global burden of disease. Approximately 7.6 million deaths (13-15\% of total) and 92 million disability adjusted life years worldwide were attributable to high blood pressure in 2001. Hypertension is found to be commonly associated with hyperuricaemia.

This study was conducted at RMC Kanpur over the period of two years (2016-2018). Total 400 patients were enrolled in this study of which, 200 patients (Hypertensive) were taken as case (Hypertensive) and, 200 patients were taken as control (non-hypertensive). Hypertensive group was further sub-categorized into two groups stage 1 (H1) and stage 2 (H2) based on Stage of hypertension (According to JNC VII classification of hypertension).

In the present study when the complication of hypertension in patients having raised serum uric acid was compared to those having normal serum uric acid it was found that $39 \%$ hyperuricaemic patients developed hypertensive retinopathy while only $24 \%$ normouricaemic patients develops hypertensive retinopathy (p value=0.02).Vishnu R. S., L. K. Dash, and Malati Murmu (2005) found that in their study, out of 150 hypertensive patients $18 \%$ developed hypertensive retinopathy. ${ }^{5}$

In our study albuminuria was found in $32 \%$ of hyperuricaemic hypertensive patients while only $18.2 \%$ normouricaemic patients developed albuminuria ( $p$ value $=0.02$ ), $42 \%$ of hyperuricaemic hypertensive developed raised serum creatinine level in comparison to normouricaemic patients $29 \%$ ( $p$ value $=0.04$ ) showing that hyperuricaemic hypertensive patients developed more albuminuria and raised serum creatinine compared to normouricaemia. In a study done by Chung-Sheng Lin, WenLing Lee, Yi-Jen Hung, et.al (2005) it was showed that in comparison to the normouricaemic patients $44 \%$ of hyperuricaemic hypertensive patients developed albuminuria.6,3 Vishnu R. S., L. K. Dash, and Malati Murmu (2010) found that in his study albuminuria was found to be present in $27 \%$ hyperuricaemic patients. ${ }^{5,4}$ Rudolf $\mathrm{P}$, Obermayr, Georg Gutjahr, et al (2008) showed that elevated levels of uric acid independently increase the risk for new onset kidney disease. This shows that our study is in concordance with other studies. 7,8

On comparing complications like CVA in our study, $12 \%$ hyperuricaemic hypertensive patients developed CVA and only $2.6 \%$ of normouricaemic patients developed CVA ( $p$ value $=0.007$ ) showing that hyperuricaemic hypertensive patients are more prone for developing CVA.

In present study $9 \%$ patients of hyperuricaemic hypertensive group had Left ventricular hypertrophy in ECG and hypertensive heart disease in ECHO while $4.3 \%$ of normouricaemia patients developed LVH in ECG and hypertensive heart disease in ECHO ( $p$ value $=0.006$ ). Vishnu, R. S., L. K. Dash, and Malati Murmu (2010) found that "Left ventricular hypertrophy (LVH) by ECG Criteria was observed 
in 31\% hyperuricaemic hypertensive patients. Chung-Sheng Lin, Wen-Ling Lee, Yi-Jen Hung, et al (2010) showed that 12\% of hyperuricaemic hypertensive patients developed LVH in ECG in comparison to the normouricaemic patients. Our study is in concordance with above mentioned studies. ${ }^{5}$

\section{CONCLUSION}

The patients having high serum uric acid levels were at high risk of developing complications like hypertensive retinopathy, albuminuria, raised serum creatinine, CVA, and cardiac complications. Hence we conclude that serum uric acid is an independent marker for incidence, severity, and complications of hypertension.

\section{REFERENCES}

[1] Rosenfeld L. The chemical work of Alexander and Jane Marcet. Clinical Chemistry 2001;47(4):784-92.

[2] Niskanen LK, Laaksonen DE, Nyyssönen K, et al. Uric Acid level as a risk factor for cardiovascular and allcause mortality in middle-aged men: a prospective cohort study. Arch Intern Med 2004;164(14):1546-51.
[3] Messerli FH, Frohlich ED, Dreslinski GR, et al. Serum Uric Acid in essential hypertension: an indicator of renal vascular involvement. Annuls of Internal Medicine 1980;93(6):817-21.

[4] Bulpitt CJ. Serum Uric Acid in hypertensive patients. British Heart J 1975;37(12):1210-5.

[5] Vishnu RS, Dash LK, Murmu M. Observation of Serum Uric Acid levels in essential hypertension. Kerala Medical J 2013;6(3).

[6] Lin CS, Lee WL, Hung YJ. Hyperuricaemia and renal function. Current Hypertension Reports 2005;3(3):197-202.

[7] Obermayr RP, Temml C, Gutjahr G, et al. Elevated uric acid increases the risk for kidney disease? Journal of the American Society of Nephrology 2008;19(12):2407-13.

[8] Tykarski A. Evaluation of renal handling of uric acid in essential hypertension: hyperuricaemia related to decreased urate secretion. Nephrology 1991;59(3):364-8. 